\title{
Nycteribiidae (Diptera, Hippoboscoidea) no Sul do Brasil ${ }^{1}$
}

\section{Gustavo Graciolli ${ }^{2}$}

1 Contribuição número 1525 do Departamento de Zoologia, Universidade Federal do Paraná.

2 Departamento de Zoologia, Universidade Federal do Paraná. Caixa Postal 19020, 81531-980 Curitiba, Paraná, Brasil. E-mail: ggraciolli@yahoo.com.br

\begin{abstract}
Nycteribiidae (Diptera, Hippoboscoidea) in the Southern Region of Brazil. A survey of nicteribiid bat flies was carried out in the Southern Region of Brazil. Twelve species of Basilia Miranda-Ribeiro, 1903 were recorded on eight species of bats. The number of species of Basilia decreased north to south. In the State of Paraná nine species were found, eight in Santa Catarina and four in Rio Grande do Sul. Basilia juquiensis Guimarães, 1943 and B. producta Maa, 1968 were recorded for the first time from Santa Catarina and B. plaumanni Scott, 1940 from Rio Grande do Sul. Myotis nigricans (Schinz, 1821) is been reported as a new host for B. producta and Myotis riparius Handley, 1960 for B. juquiensis. The male of Basilia lindolphoi Graciolli, 2001 is described. Key for the collected species of Basilia is given.

KEY WORDS. Bat flies, Chiroptera, ectoparasite, hosts, taxonomy, Vespertilionidae.
\end{abstract}

RESUMO. Um levantamento taxonômico das espécies de Nycteribiidae e de seus hospedeiros foi realizado na Região Sul do Brasil, utilizando material depositados em coleções e dados de literatura. Foram encontradas um total de 12 espécies de Basilia Miranda-Ribeiro, 1903 sobre oito espécies de morcegos pertencentes as famílias Phyllostomidae e Vespertilionidae. Considerando o número de espécies por estado, houve um decréscimo no sentido norte-sul. No Paraná, foram encontradas nove espécies, em Santa Catarina oito e no Rio Grande do Sul quatro. Basilia speiseri (Miranda-Ribeiro, 1907) é registrada pela primeira vez nos estados do Paraná e de Santa Catarina. Basilia juquiensis Guimarães, 1943 e B. producta Maa, 1968 são novos registros para Santa Catarina e B. plaumanni Scott, 1940 é registrada pela primeira vez no Rio Grande do Sul. Myotis nigricans (Schinz, 1821) é registrado pela primeira vez como hospedeiro de B. producta e Myotis riparius Handley, 1960 de B. juquiensis. O macho de Basilia lindolphoi Graciolli, 2001 é descrito. Chave para as espécies de Basilia encontradas é disponibilizada. PALAVRAS CHAVE. Chiroptera, ectoparasito, hospedeiro, taxonomia, Vespertilionidae.

A família Nycteribiidae é compreendida por moscas hematófagas, exclusivamente ectoparasitas de morcegos. As espécies têm o mesonoto reduzido e despigmentado e as pleuras deslocadas para a face dorsal devido à expansão do esterno torácico, tornando-as com um aspecto acariforme (Figs 1-2). O comprimento do corpo varia de 1,5 a $5 \mathrm{~mm}$ (Peterson \& Wenzel 1987). Como nas outras famílias de Hippoboscoidea, o desenvolvimento da larva ocorre no útero da mãe, onde é alimentada através de glândulas que produzem uma substância nutritiva. No terceiro ínstar, a larva é expelida e depositada no substrato do abrigo onde passa para o estágio de pupa.

Atualmente, a família compreende 260 espécies, incluídas em 13 gêneros e três subfamílias, Nycteribiinae, Cyclopodiinae e Archinycteribiinae (MAA 1989).

No continente americano, são encontrados dois gêneros de Nycteribiinae, Basilia Miranda-Ribeiro, 1903 e Hershkovitzia Guimarães \& D'Andretta, 1956.

Hershkovitzia é endêmico da Região Neotropical e são conhecidas quatro espécies que parasitam morcegos da família Thyropteridae (Peterson \& LaCey 1985). No Brasil, foram registradas duas espécies, $H$. cabala Peterson \& Lacey, 1985 (Graciolli 2001) e H. inaequalis Theodor, 1967 (Graciolli \& BERNARd 2002), ambos os registros na região Amazônica.

Basilia é o gênero com maior número de espécies dentro de Nycteribiidae, atualmente acima de 100, sendo 47 exclusivamente americanas. As espécies são encontradas em todos os continentes e parasitam principalmente morcegos da família Vespertilionidae.

Em relação aos estados da Região Sul do Brasil, apenas no Paraná já havia sido realizado um levantamento taxonômico. Graciolli \& Carvalho (2001) registraram sete espécies, sendo um novo registro para o Brasil, dois novos para o estado e uma espécie do grupo speiseri, até então desconhecida para a ciência, foi descrita. Nos estados de Santa Catarina e Rio Grande do Sul foram registradas apenas quatro e uma espécies, respectivamente. 
O presente trabalho tem como objetivo realizar um levantamento taxonômico das espécies de Nycteribiidae e de seus hospedeiros na Região Sul do Brasil.

\section{MATERIAL E MÉTODOS}

Para a realização deste trabalho, além dos dados de literatura, foram examinados espécimens preservados em via líquida, montados em lâminas e secos provenientes das seguintes instituições brasileiras: Coleção de Entomologia Padre Jesus Santiago Moure do Departamento de Zoologia, Universidade Federal do Paraná, Curitiba, Paraná (DZUP); Museu de História Natural Capão da Imbuia, Curitiba, Paraná (MHNCI); Museu de Zoologia da Universidade de São Paulo, São Paulo (MZSP); Museu de Ciências Naturais, Fundação Zoobotânica do Rio Grande do Sul, Porto Alegre (MCNZ).

A terminologia adotada para a morfologia de Nycteribiidae segue Peterson \& Wenzel (1987) (Figs 1-3, 35).

Em relação à classificação e nomes científicos das espécies de Chiroptera (Mammalia), segue-se Koopman (1993) e, exclusivamente para a família Molossidae, Gregorin \& TAdDeI (2002).

\section{RESULTADOS E DISCUSSÃO}

Foram registradas 12 espécies de Basilia dos grupos morfológicos speiseri, juquiensis e ferruginea sobre nove espécies de morcegos das famílias Vespertilionidae e Phyllostomidae (Apêndice 1).

Chave de identificação para as fêmeas das espécies de Basilia Miranda-Ribeiro, 1903 da Região Sul do Brasil

1. Margem posterior do tergito II com dois lóbulos com setas espiniformes longas e curtas (Figs 17-21) ……................. 8

$1^{\prime}$. Margem posterior do tergito II arqueada, levemente fendida na linha mediana (Figs 9-16)

2. Tergito II com margens laterais subparalelas (Fig. 16). Esternito III encoberto pelo esternito II (Fig. 29) ............ $B$. juquiensis

2'. Tergito II com margens laterais convergentes (Figs 9-15). Esternito III visível (Figs 22-29)

3. Tíbias com quatro fileiras de setas sob sulcos na face ventral (Fig. 7). Ctenídeo com dentes separados (Fig. 26)

B. hughscotti

3'. Tíbias com três fileiras de setas sob sulcos na face ventral (Fig. 6). Ctenídeo com dentes justapostos (Figs 22-24, 27 28) .

4. Sensila na margem anterior do fêmur II presente (Fig. 5) .. B. speiseri

4'. Sensila na margem anterior fêmur II ausente (Fig. 4) ...... 5

5. Esternito II mais longo que largo (Fig. 22) B. andersoni
5'. Esternito II mais largo que longo (Figs 23-24, 27) ........... 6

6. Margem anterior do tergito I arredondada (Fig. 10) B. carteri

6'. Margem anterior do tergito I subtrapezóide (Figs 11, 14) .

Notopleura com 11 setas. Tergito I mais longo que largo com 15 setas longas na margem posterior truncada (Fig. 11). B. currani

7'. Notopleura com nove setas. Tergito I mais longo que largo com margem anterior arredondada (Fig. 14)

B. lindolphoi

8. Tíbias com quatro fileiras de setas transversais sobre sulcos na face ventral (Fig. 8) .. 9

8'. Tíbias com três fileiras de setas transversais sobre sulcos na face ventral (Fig. 6) 10

9. Conetivo abdominal dorsal com setas pustuladas entre o tergito II e o segmento anal (Fig. 21). Esternito V dividido longitudinalmente na linha média (Fig. 31) ......... B. ruiae

9'. Conetivo abdominal dorsal glabro (Fig. 17). Esternito V inteiro (Fig. 30) B. ferruginea

10. Conjunto de pêlos sensoriais na margem anterior dos fêmures II e III presente (Fig. 5). Lóbulos do tergito II mais ou tão largos que longos (Figs 19-20) 11

10'. Conjunto de pêlos sensoriais na margem anterior dos fêmures II e III ausentes (Fig. 4). Lóbulos do tergito II muito finos (Fig. 18) B. ortizi

11. Tergito I com oito setas mais longas que o tergito de cada lado na margem posterior (Fig. 20) B. producta

$11^{\prime}$. Tergito I com todas as setas curtas na margem posterior (Fig. 19) B. plaumanni

\section{Nycteribiidae Samouelle, 1819 Basilia Miranda-Ribeiro, 1903}

Basilia Miranda-Ribeiro, 1903: 177; Speiser, 1908: 437, syn. Pseudelytromyia; Ferris, 1924: 191 (sinopse das espécies americanas); Curran, 1935: 2 (chave de identificação das espécies americanas); Del Ponte, 1944: 123 (chave de identificação das espécies americanas); Guimarães, 1946: 18 (revisão taxonômica das espécies sul-americanas); Guimarães \& D'Andretta, 1956: 1 (sinopse das espécies americanas), 19, syn. Guimaraesia; Peterson, 1960: 31 (chave de identificação das espécies neárticas); Guimarães, 1966: (chave de identificação das espécies panameias); Guimarães, 1972: (chave de identificação das espécies venezuelanas) Theodor, 1967: 192 (diagnose), 247 (chave de identificação específica de fêmeas), 250 (chave de identificação específica de machos); Peterson, 1971: 1 (chave de identificação das espécies costaricensis); Graciolli \& Carvalho, 2001: 33 (chave pictórica de identificação espécies paranaenses). 

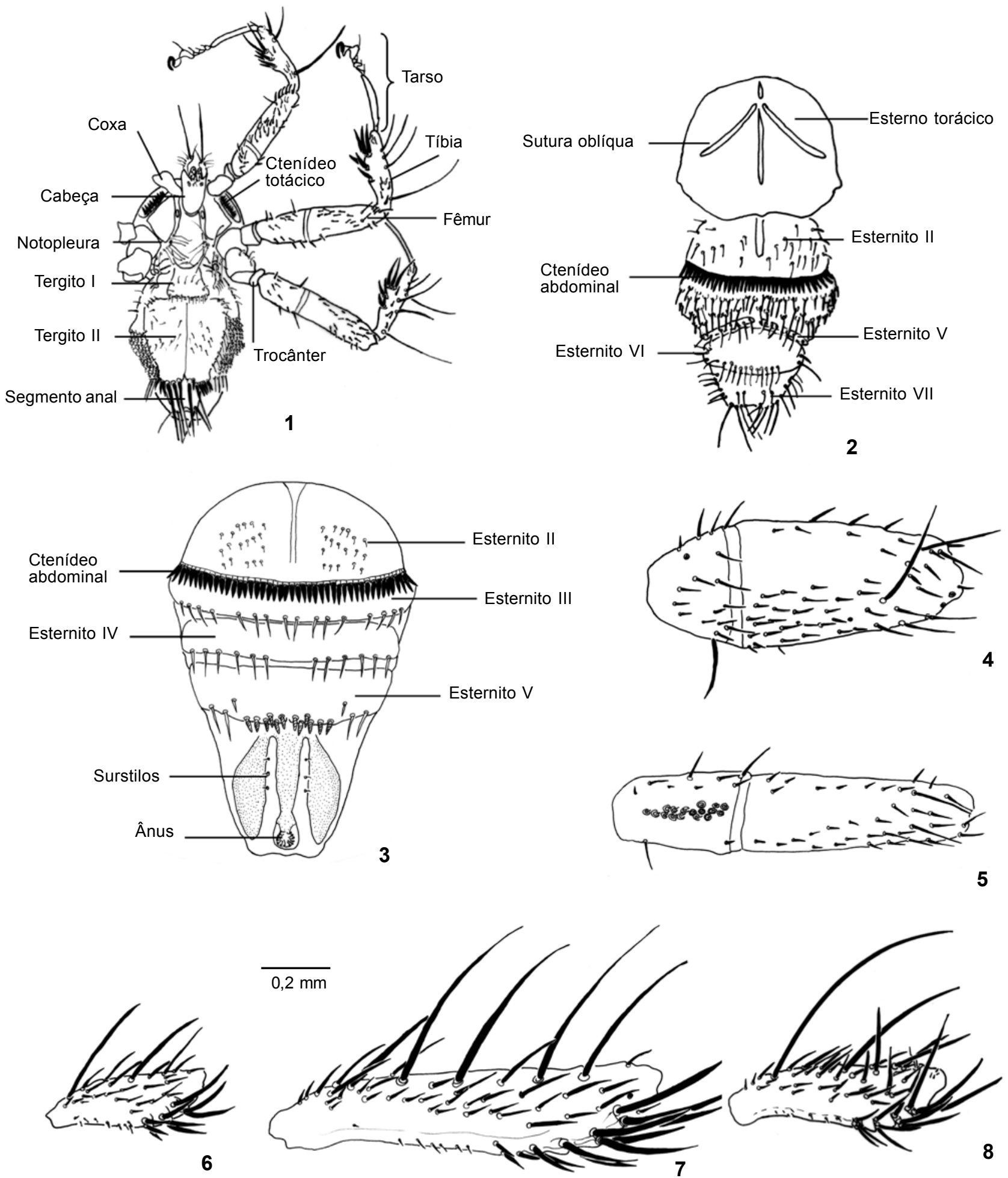

Figuras 1-8. (1-2) Fêmea de Basilia plaumanni: (1) vista dorsal; (2) vista ventral, pernas omitidas; (3) Abdômen de Basilia sp., macho em vista ventral; (4-5) fêmur III de: (4) B. ruaie; (5) B. plaumanni; (6-8) tíbia II de: (6) B. juquiensis; (7) B. hughscotti; (8) B. ruiae. 


\section{Pseudelytromyia Miranda-Ribeiro, 1907: 233.}

Guimarãesia [sic] Schuurmans-Stekhoven Jr., 1951a: 109. Espécie-tipo de Basilia: Basilia ferruginea Miranda-Ribeiro, 1903, por designação original.

Espécie-tipo de Pseudelytromyia: Pseudelytromyia speiseri MirandaRibeiro, 1907, por monotipia.

Espécie-tipo de Guimaraesia: Guimaraesia guimaraesi Schuurmans-Stekhoven Jr., 1951, por designação original.

Diagnose (modificada de THEODOR 1967). Cabeça comprimida lateralmente. Olhos geralmente bifacetados e implantados em pedestal único, cilíndrico e pigmentado. Vértice esclerotinizado e com quatro a vinte setas. Palpos foliáceos, com duas fileiras ventrais de setas e uma seta apical longa. Peças bucais com o labelo mais curto que o premento. Tórax mais largo que longo. Suturas notopleurais subparalelas, com placas laterais geralmente largas e apresentando uma fileira de setas. Fêmea com elevação posterior do mesonoto conspícua. Halteres presentes. Ctenídios torácicos formados por dentes finos e pontudos. Tíbias predominantemente pouco comprimidas e pouco dilatadas, com três a cinco fileiras transversais de setas na borda ventral. Basitarso muito mais longo que os restantes tarsômeros somados. Abdômen com sete pares de espiráculos; abdômen do macho com segmentação normal; quinto esternito do macho com várias cerdas espiniformes na borda posterior. Abdômen da fêmea com dois a três tergitos; terceiro e quarto esternitos do abdômen sem placas esclerotinizadas. Esternito I delgado, com setas na borda posterior. Ctenídio abdominal formado de setas espiniformes. Esternito V dividido. Fêmea com esclerito mediano pós-anal geralmente presente e com apenas uma placa genital dorsal ligada ao esclerito mediano pós-anal.

\section{Grupo speiseri \\ Basilia andersoni Peterson \& Maa, 1970} Figs 9, 22, 36

Basilia andersoni Peterson \& Maa, 1970: 1480, localidade-tipo: Departamento Tacuarembo, Uruguai; Graciolli \& Carvalho, 2001: 34 (diagnose).

Diagnose. Cabeça. Vértice com três pares de setas, um par e uma seta acessória entre os olhos. Olhos bifacetados sem base pigmentada.

Tórax. Notopleura com nove setas. Mesonoto sem elevação conspícua. Tíbias com três filas esculturadas de setas transversais sob sulcos na face ventral.

Fêmea. Abdômen - tergito I com poucas setas discais, mais longo que largo, em vista dorsal, pentagonal. Tergito II subcordiforme, com poucas setas discais. Margem posterior do tergito com cinco a seis setas longas. Segmento anal com margens laterais convergentes. Conetivo abdominal lateral com setas curtas (Fig. 9). Esternito II mais longo que largo; ctenídeo com setas espiniformes justapostas. Esternitos VI e VII divididos longitudinalmente no ponto médio (Fig. 22).
Macho. Abdômen - esternito II mais longo que largo, ctenídeo com setas espiniformes justapostas. Esternito V com 12 setas espiniformes. Parâmero mais alto que longo no ápice com poucas setas. Edeago com margem dorsal serreada na região apical.

Hospedeiro-tipo. Myotis nigricans (Vespertilionidae). Outros hospedeiros. Eptesicus brasiliensis, Myotis sp. e Histiotus velatus (Vespertilionidae).

Distribuição geográfica. Brasil (Paraná e Rio Grande do Sul) e Uruguai.

Material examinado: Paraná: Araucária (Refinaria Presidente Getúlio Vargas), 27/III/2001, 3 machos e 7 fêmeas (hosp. Myotis sp, DZUP), F.C. Passos leg.; Curitiba: Centro Politécnico, 14/XI/2002 (2 machos e 2 fêmeas, hosp. Myotis sp., DZUP), E.A. de Castro leg.; Rio Grande do Sul: Maquiné (Estação de Pesquisa e Produção de Maquine, Fundação de Pesquisa Agropecuária da Secretaria da Agricultura do estado do Rio Grande do Sul - FEPAGRO), 16/I/2001, 2 machos e 2 fêmeas (hosp. Myotis sp., DZUP), Graciolli, Rui \& Leopoldo leg.

Comentário. Parátipos de B. andersoni foram removidos de Histiotus velatus e Eptesicus brasiliensis conservados em via líquida. No entanto, estes registros devem ser acidentais; pois cerca de $95,6 \%$ do material-tipo de $B$. andersoni $(n=45)$ foi encontrado sobre Myotis nigricans e outros exemplares examinados sobre Myotis sp.

\section{Basilia carteri Scott, 1936}

Figs 10, 23, 37

Basilia carteri Scott, 1936: 498, localidade-tipo: Mathlawaiya, Paraguai; Scott, 1940: 57; Guimarães, 1946: 49 (redescrição); Guimarães \& D’Andretta, 1956: 98 (figs 151, 156 a 159, 161, 166), 99, syn. Basilia romanai; Theodor, 1967: 271 (diagnose); Autino et al., 1999: 141 (redescrição); Graciolli \& Carvalho, 2001: 37 (diagnose); Graciolli et al., 2003: 403 (registro).

Basilia romanai Del Ponte, 1944: 119, localidade-tipo: El Zanpon, Santiago del Estero, Argentina.

Guimarãesi [sic] carteri; Schuurmans-Stekhoven Jr., 1951a: 112. Guimaraesi romanai; Schuurmans-Stekhoven Jr., 1951a: 112.

Guimaraesi romanai; Schuurmans-Stekhoven Jr., 1951b: 551 (redescrição).

Diagnose. Cabeça. Vértice com três pares de setas dorsais anteriores e um par de setas menores mediana entre os olhos com uma seta acessória posterior no lado esquerdo ou direito. Olhos bifacetados com base pigmentada.

Tórax. Notopleura com 12 a 13 setas. Mesonoto com expansão posterior conspícua. Tíbias com três filas de setas transversais sob sulcos na face ventral.

Fêmea. Abdômen - tergito I mais longo que largo, com poucas setas discais, margem posterior com oito a nove setas longas e largas. Tergito II subcordiforme, com margem posterior arredondada, reentrante na linha média, sem formar lóbulos, com poucas setas discais. Segmento anal com margens la- 

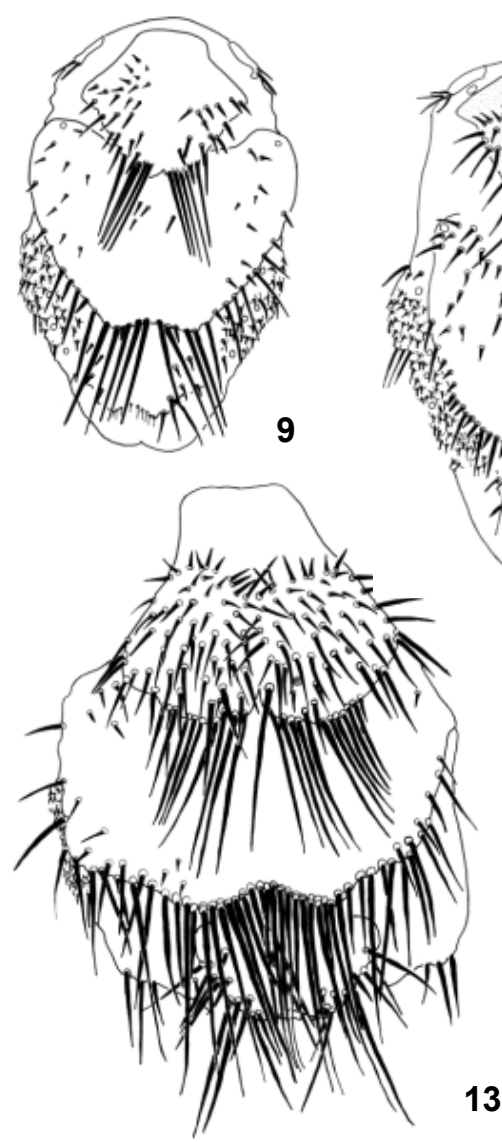
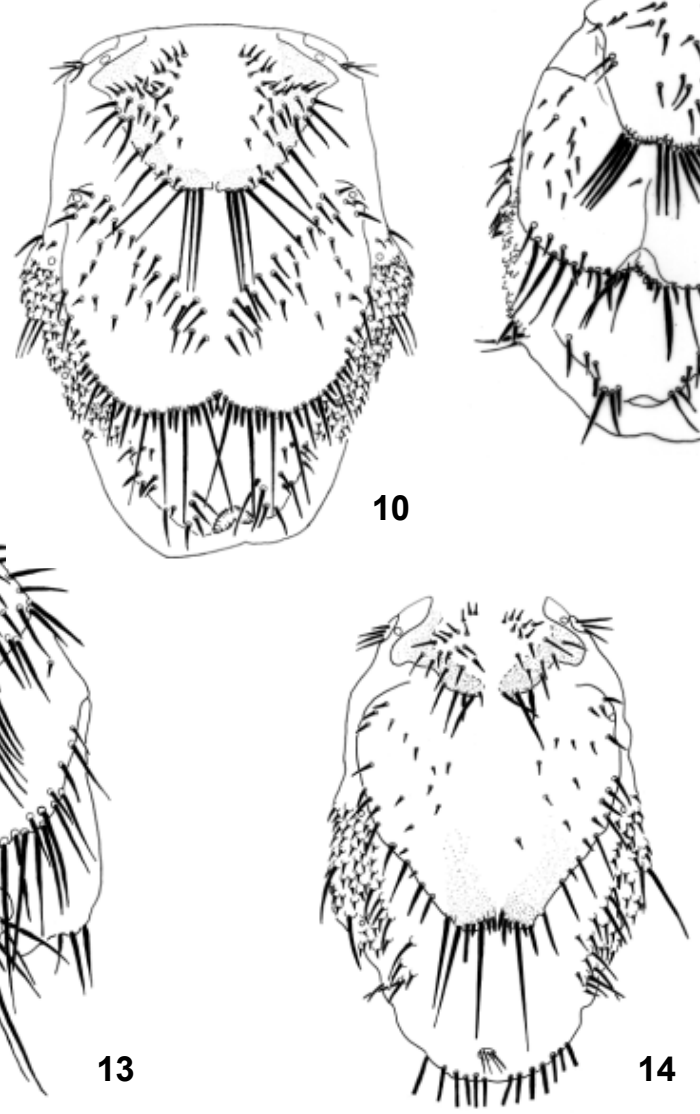
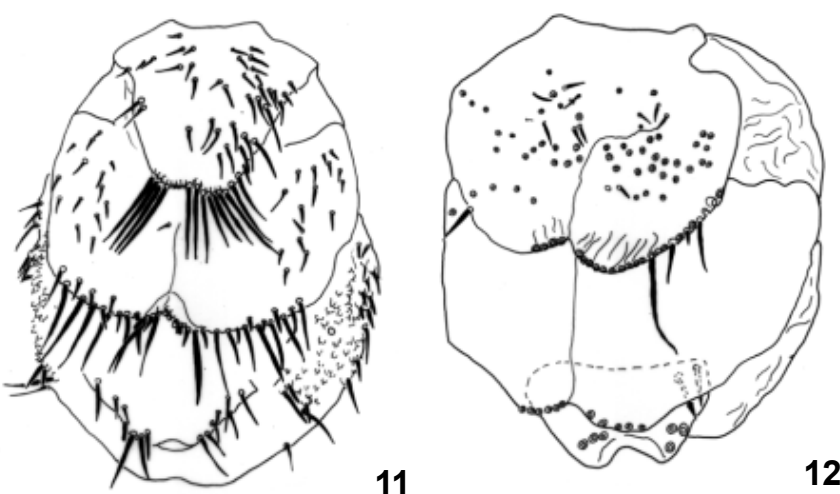

Figuras 9-16. Abdômen de Basilia, fêmea em vista dorsal: (9) B. andersoni, parátipo, modificado de Graciolu \& Carvalho (2001); (10) Basilia carteri, modificado de Graciolu \& Carvalho (2001); (11) B. currani, holótipo; (12) B. hughscotti, holótipo; (13) B. hughscotti do Distrito Federal; (14) B. lindolphoi, modificado de Gracioll \& Carvalho (2001); (15) B. speiseri; (16) B. juquiensis, modificado de Gracioll \& Carvalho (2001).

terais convergentes. Conetivo abdominal lateral com setas curtas (Fig. 10). Esternito II mais largo que longo; ctenídeo com setas espiniformes justapostas. Esternito VI dividido longitudinalmente na linha média. Esternito VII inteiro (Fig. 23).

Macho. Abdômen - esternito II mais largo que longo; ctenídeo com setas espiniformes justapostas. Esternito V com 25 setas espiniformes na margem posterior, em duas filas irregulares. Parâmero subretangular com quatro setas. Edeago com margem dorsal serreada na região basal e com um processo ventral apical.

Hospedeiro-tipo. Molossops temmincki (Molossidae). Outros hospedeiros. Eptesicus brasiliensis, E. diminutus, E. furinalis, Myotis albescens, M. keaysi, M. levis, M. nigricans, Myotis riparius, M. ruber, Myotis sp., (Vespertilionidae); Molossus molossus e Tadarida brasiliensis (Molossidae).

Distribuição geográfica. Brasil (Mato Grosso, São Paulo, Paraná e Santa Catarina), Bolívia, Paraguai e Argentina (Jujuy, Tucumán, Salta e Santiago del Estero).
Material examinado. Paraná: Diamante do Norte, 18/XII/ 1997, 1 macho e 1 fêmea (hosp. Eptesicus brasiliensis, MHNCI).

Comentário. Espécie anteriormente registrada por THEODOR (1967) em Nova Teutônia, Santa Catarina, sendo este o limite meridional de distribuição, sobre Myotis albescens. Espécie com baixa especificidade parasitária, exclusivamente sulamericana.

\section{Basilia currani Guimarães, 1943}

Figs 11, 24, 36

Basilia carteri; Scott, 1940: 60 (part., discussão). Erro de identificação.

Basilia currani Guimarães, 1943: 257, localidade-tipo: São Paulo, São Paulo, Brasil; Guimarães, 1946: 14 (redescrição); Guimarães \& D'Andretta, 1956: figs 140-143; Theodor, 1967: 276 (diagnose).

Guimaraesia currani; Schuurmans-Stekhoven Jr., 1951a: 112.

Guimaraesia romanai; Schuurmans-Stekhoven Jr., 1951b: 551. Erro de identificação.

Revista Brasileira de Zoologia 21 (4): 971-985, dezembro 2004 
Diagnose. Cabeça. vértice com quatro setas, sendo um par entre os olhos. Olhos bifacetados com base pigmentada.

Tórax. Notopleura com 11 setas. Mesonoto com expansão posterior conspícua. Tíbias com três filas de setas transversais sob sulcos na face ventral.

Fêmea. Abdômen - tergito I mais longo que largo com 15 setas longas na margem posterior. Tergito II subcordiforme com 15 setas na margem posterior. Segmento anal com margens laterais convergentes. Conetivo abdominal lateral com setas curtas (Fig. 11). Esternito II mais largo que longo, ctenídeo com setas espiniformes justapostas. Esternito VI dividido, cada esclerito com margem interna mais longa que a externa. Esternito VII inteiro (Fig. 24).

Macho. Abdômen - esternito II mais largo que longo; ctenídeo com setas espiniformes justapostas. Esternito V com 20 a 25 setas espiniformes na margem posterior dispostas em duas filas. Parâmero com ápice triangular com setas presentes na base e no ápice. Edeago liso com ápice truncado.

Hospedeiro-tipo. Myotis ruber (Vespertilionidae). Outros hospedeiros. Eptesicus brasiliensis, Myotis albescens, M. chiloensis, M. levis (Vespertilionidae) e Tadarida brasiliensis (Molossidae).

Distribuição geográfica. Brasil (São Paulo e Santa Catarina) e Argentina (Catamarca, Tucumán e La Rioja).

Material examinado. Santa Catarina: Seara (Nova Teutônia), 29/VII/1928, 1 macho e 1 fêmea (hosp. Myotis sp., provavelmente albescens, MZSP), F. Plaumann leg.

Material adicional examinado. São Paulo: São Paulo, sem data, 1 fêmea (Holótipo, hosp. Myotis ruber, MZSP).

Comentário. Basilia currani é encontrada principalmente sobre espécies de Myotis Kaup, 1829. Na Argentina, esta mosca foi encontrada somente sobre Myotis levis (Autino et al. 2000) e no Brasil, sobre Myotis ruber e Myotis albescens (Gracioldi 2001).

\section{Basilia hughscotti Guimarães, 1946 Figs $7,12,13,25,26,36$}

Basilia hughscotti Guimarães, 1946: 77, localidade-tipo: São Lourenço das Missões, Rio Grande do Sul, Brasil; Guimarães \& D'Andretta, 1956: figs 181, 193, 194; Graciolli \& Aguiar, 2002: 178 (registro).

Basilia sp., Whitaker Jr. \& Mumford, 1977: 257 (registro).

Diagnose. Cabeça. Vértice com 12 setas entre os olhos e 14 na margem anterior. Olhos bifacetados com a base pigmentada. Cabeça inserida no meio do tórax.

Tórax. Notopleura com 13 setas. Mesonoto com elevação posterior. Sensila na margem anterior do fêmur II com oito pêlos sensoriais e fêmur III com 10 a 11. Tíbias com quatro filas de setas transversais sob sulcos na face ventral (Fig. 7).

Fêmea. Abdômen - tergito I hexagonal, tão longo quanto largo, fendido na margem anterior e com uma faixa longitudinal despigmentada e glabra. Tergito II subcordiforme com poucas setas discais; setas marginais mais longas que as outras setas. Segmento anal com margens laterais convergentes. Conetivo abdominal lateral com setas curtas (Fig. 13). Esternito
II mais largo que longo; ctenídeo com dentes esparsos e com setas normais entre eles. Esternitos VI e VII divididos (Fig. 26). Macho não descrito.

Hospedeiro-tipo. Chrotopterus auritus (Phyllostomidae). Outro hospedeiro. Eptesicus furinalis, Myotis nigricans e Myotis riparius (Vespertilionidae).

Distribuição geográfica. Brasil (Distrito Federal, Minas Gerais e Rio Grande do Sul).

Material examinado. Rio Grande do Sul: São Lourenço das Missões, 1904, 1 fêmea (Holótipo) e 1 fêmea, hosp. Chrotopterus auritus, MZSP), Enslen leg.

Material adicional examinado. Distrito Federal: Área de Proteção Ambiental Cabeça do Veado, 25/VII/1998, 1 fêmea (hosp. Myotis nigricans, DZUP), L.S. Aguiar leg.

Comentário. Basilia hughscotti foi descrita por GUIMARÃES (1946) que baseou-se apenas em um indivíduo fêmea. O holótipo encontra-se em péssimo estado de conservação (Figs 12, 25). Quase a totalidade das suas setas foram perdidas, assim como a pigmentação. Em 1974, o holótipo foi emprestado a B.V. Peterson, provavelmente com o objetivo de compará-lo com espécimens coletados por WhitaKer \& MUMFord (1977) no estado de Minas Gerais, que o pesquisador considerava como prováveis espécies não descritas. No MZSP foi encontrado um recipiente contendo três exemplares de Basilia com os mesmos dados de coleta que o holótipo de B. hughscotti, sendo um dos exemplares, uma fêmea de $B$. hughscotti e os outros provavelmente Basilia plaumanni. No entanto, o estado do material é precário, este fato sugere que o hospedeiro-tipo de B. hughscotti possa ser resultado de uma contaminação.

\section{Basilia lindolphoi Graciolli, 2001 Figs 14, 27, 34, 35, 36}

Basilia lindolphoi Graciolli, 2001: 38, localidade-tipo: Rio Branco do Sul, Paraná, Brasil; Graciolli et al., 2003: 403 (registro).

Diagnose. Cabeça. Vértice com três pares de setas; dois pares anteriores na margem e um par menor, mais discal e anterior aos olhos. Olho bifacetado sobre base não pigmentada.

Tórax. Notopleura com nove setas. Mesonoto com expansão posterior conspícua. Tíbias com três filas de setas transversais sob sulcos na face ventral.

Fêmea. Abdômen - tergito I mais largo que longo com poucas setas discais distribuídas irregularmente e na margem posterior, dois grupos de quatro setas maiores que as demais setas. Tergito II subcordiforme, margem posterior reta ou plana com uma seta longa de cada lado subapical e uma a três setas espiniformes longas e três a cinco setas espiniformes curtas. Segmento anal com margem lateral convergente. Conetivo abdominal lateral com setas curtas (Fig. 14). Esternito II mais largo que longo, ctenídeo com setas espiniformes justapostas. Esternitos VI e VII divididos longitudinalmente na linha média. Esternito VI com cada esclerito com margem interna mais longa que a externa (Fig. 27). 

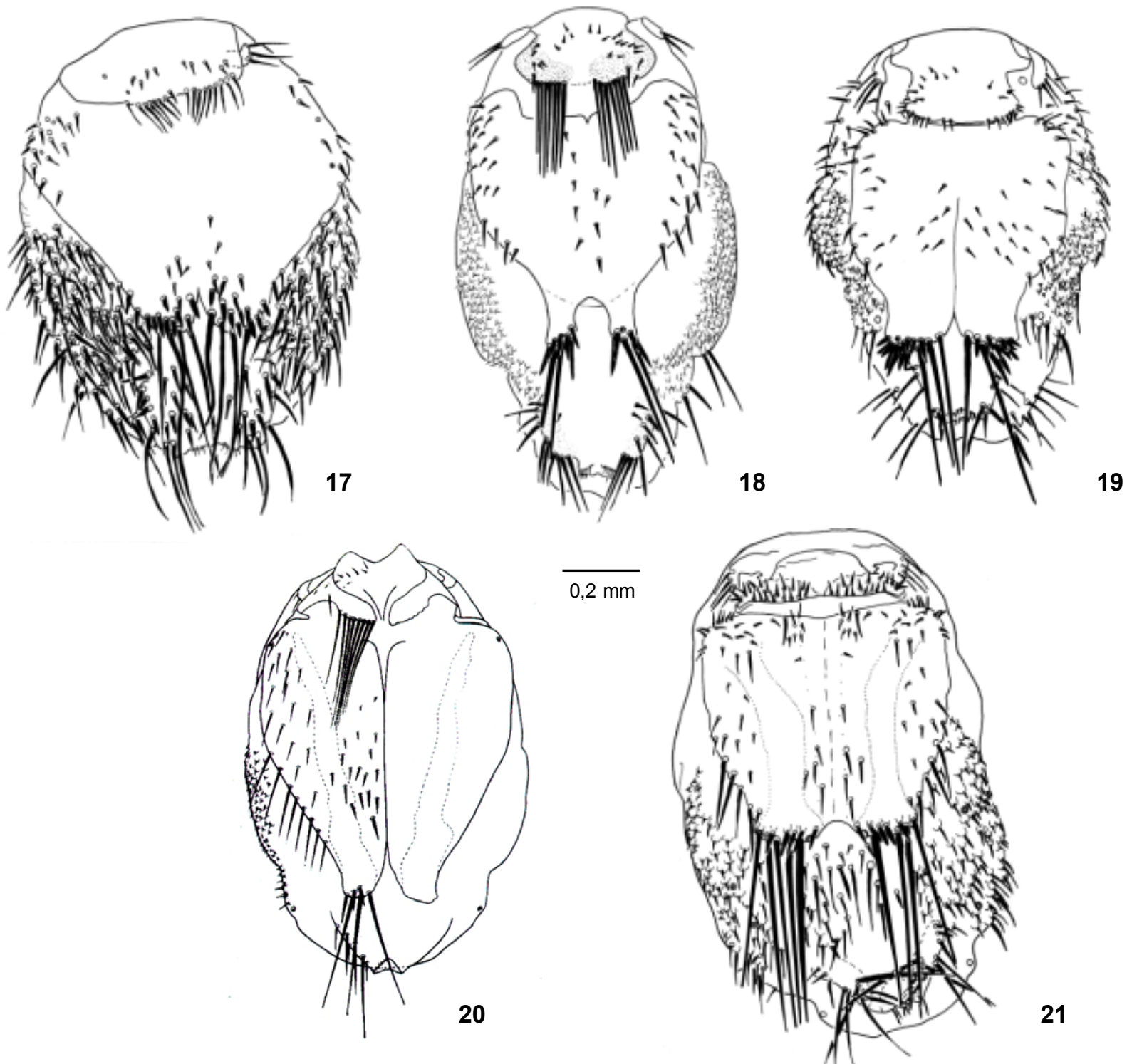

21

Figuras 17-21. Abdômen de Basilia, fêmea em vista dorsal; (17) B. ferruginea do Estado do Rio de Janeiro; (18) B. ortizi, modificado de Graciolli \& Carvalho (2001); (19) B. plaumanni; (20) B. producta, modificado de MaA (1968), em diferente escala; (21) B. ruiae Graciolli, modificado de Gracioll (2003).

Macho. Abdômen - tergitos I a VI sem setas discais. Tergitos II a IV com setas na margem posterior mais longas que o tergito. Esternito II mais largo que longo, ctenídeo com cerca de 65 setas espiniformes justapostas. Esternito V com nove setas dispostas em duas filas na margem posterior (Fig. 34). Cercos alcançando a margem posterior do esternito V. Parâmero levemente constrito na região mediana e ápice pontiagudo, com sete setas. Apódema do edeago levemente curvado. Edeago com margem superior serreada na região apical (Fig. 35).
Hospedeiro-tipo. Myotis nigricans (Vespertilionidae). Outros hospedeiros. Myotis riparius, Myotis sp. (Vespertilionidae); e Mimon bennettii (Phyllostomidae).

Material examinado. Paraná: Rio Branco do Sul (Gruta da Lancinha II), 15/III/1988, 1 fêmea (Holótipo, hosp. Myotis nigricans, DZUP), S.S.P. Silva leg., 13/III/1998, 1 fêmea (hosp. Mimon bennettii, DZUP), S.S.P. Silva leg.; 15/III/1998, 1 fêmea (hosp. M. bennettii, DZUP), SSP Silva leg.; Tunas do Paraná (Parque Estadual de Campinhos, Gruta de Campinhos), 28/IX/2003, 
1 macho e 1 fêmea (hosp. Myotis sp., DZUP), I.S. Arnoni leg.; Santa Catarina: Botuverá (Parque Natural de Botuverá, Gruta de Botuverá I), 02/II/2003, 1 macho e 2 fêmeas (hosp. Myotis sp., DZUP), G. Graciolli \& I.S. Arnoni leg.

Distribuição geográfica. Brasil (São Paulo, Paraná e Santa Catarina).

Comentário. Novo registro para o Estado de Santa Catarina. Basilia lindolphoi foi descrita por Graciolli (2001) a partir de um único exemplar fêmea. Esta espécie é muito semelhante a Basilia andersoni, B. currani e B. guimaraesi SchuurmannsStekhoven Jr., 1951. Com exceção de B. andersoni, as outras espécies são pouco representadas nas coleções científicas. PETERSON $\&$ MaA (1970) consideraram que B. andersoni apresentava características intermediárias entre B. currani e B. guimaraesi, embora não tenham examinados exemplares de $B$. guimaraesi e tampouco especificaram a procedência do material examinado de $B$. currani. Foram examinados o lectótipo e os paralectótipos de $B$. guimaraesi, e consideramo-na mais semelhante à $B$. currani do que às outras espécies, principalmente pela forma do tergito I. Pelos mesmos caracteres, $B$. lindolphoi aparenta ser mais semelhante à $B$. andersoni. A genitália masculina de B. lindolphoi e B. andersoni é muito semelhante, sendo diferenciada apenas pelo maior número de setas no parâmero da primeira espécie e pelo número de setas espiniformes no esternito V. Em B. lindolphoi são encontradas nove, enquanto em $B$. andersoni, 18 , e na presença de setas discais no tergito II de $B$. andersoni. As fêmeas de $B$. andersoni e $B$. lindolphoi são facilmente diferenciadas pelos caracteres apresentados na chave e pelo maior número de setas no esclerito anal de $B$. andersoni. Um estudo mais detalhado das quatro espécies, principalmente dos machos, é necessário.

\section{Basilia speiseri (Miranda-Ribeiro, 1907)}

\section{Figs $15,28,36$}

Nycteribia (Acrocholidia) bellardii, nec Rondanii, Speiser, 1901: 46, 61 (redescrição da fêmea).

Pseudelytromyia speiseri Miranda-Ribeiro, 1907: 233; localidade-tipo: Quinta da Boa Vista, Rio de Janeiro, Rio de Janeiro, Brasil.

Basilia speiseri, Guimarães, 1946: 67 (redescrição); Theodor, 1967: 282 (diagnose); Graciolli et al., 2003: 403 (registro). Guimaraesia speiseri, Schuurmans-Stekhoven Jr., 1951a: 112.

Diagnose. Cabeça. Vértice com dois pares de setas posteriores e um par entre os olhos. Olhos com duas a três facetas desiguais com base pigmentada.

Tórax. Notopleura com 11 setas. Mesonoto com elevação posterior. Sensila na margem anterior do fêmur III com cinco setas sensoriais. Tíbias com três filas de setas transversais sob sulcos na face ventral.

Fêmea. Abdômen - tergito I alongado, trapezóide com pequenos lóbulos na margem posterior. Cada lóbulo com três a quatro setas. Tergito II com quatro a cinco setas na margem anterior e duas discais. Segmento anal com margens laterais subparalelas. Conetivo abdominal lateral com setas curtas (Fig. 15). Esternito II mais largo que longo, ctenídeo com setas espiniformes justapostas. Esternitos VI e VII divididos ao meio longitudinalmente (Fig. 28).

Macho. Abdômen - esternito II mais largo que longo, ctenídeo com setas espiniformes justapostas. Esternito V com 26 setas espiniformes dispostas em duas fileiras. Parâmero afilado no ápice. Edeago truncado no ápice, margem dorsal serreada.

Hospedeiro-tipo. Lasiurus borealis ( = Lasiurus blossevillii) (Vespertilionidae). Outros hospedeiros. Anoura geoffroyi; Carollia perspicillata, Phyllostoma sp. (Phyllostomidae); Eptesicus brasiliensis, Myotis albescens, M. nigricans (Vespertilionidae); e Molossus obscurus (Molossidae).

Distribuição geográfica. Brasil (Mato Grosso, Rio de Janeiro, São Paulo, Paraná e Santa Catarina), Paraguai e Argentina (Santa Fé).

Material examinado. Paraná: Morretes, 24/XI/2000, 2 machos e 2 fêmeas (hosp. Myotis nigricans, DZUP), G. Graciolli leg.; Santa Catarina: Itapoá (Reserva Particular do Patrimônio Natural de Volta Velha), 20/II/2001, 2 machos e 3 fêmeas (hosp. Myotis nigricans, DZUP), G. Graciolli leg.

Comentário. Nova ocorrência para os estados do Paraná e Santa Catarina. Como B. carteri, é uma espécie restrita à América do Sul.

\section{Grupo juquiensis Basilia juquiensis Guimarães, 1946 Figs 16, 29, 37}

Basilia juquiensis Guimarães, 1946: 73 localidade-tipo: Juquiá, São Paulo, Brasil; Guimarães \& D’Andretta, 1956: 112 (diagnose); Graciolli \& Carvalho, 2001: 39 (diagnose e descrição do macho).

Guimarãesia juquiensis, Schuurmans-Stekhoven Jr., 1952a: 112. Basilia juquiensis juquiensis Theodor, 1967: 279 (diagnose).

Diagnose. Cabeça. Vértice com três pares de setas, um par entre os olhos. Olhos bifacetados sem a base pigmentada.

Tórax. Notopleura com oito a nove setas. Mesonoto sem expansão conspícua. Tíbias com três filas de setas transversais sob sulcos na face ventral.

Fêmea. Abdômen - tergito I com margem anterior arredondada, margem posterior com mais ou menos 14 setas, a maioria mais longa que o tergito. Tergito II com margens laterais subparalelas; margem posterior arredondada com alternância de setas longas e curtas. Segmento anal com margens laterais convergentes. Conetivo abdominal lateral com setas longas, tamanho uniforme e entre elas poucas setas curtas entre o quinto e sétimo espiráculos (Fig. 16). Esternito II quase duas vezes mais longo que largo, ctenídeo com setas espiniformes justapostas. Esternito III encoberto pelo esternito II. Esternito VI dividido longitudinalmente na linha média (Fig. 29). 


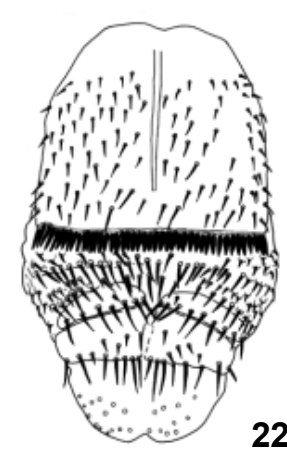

22
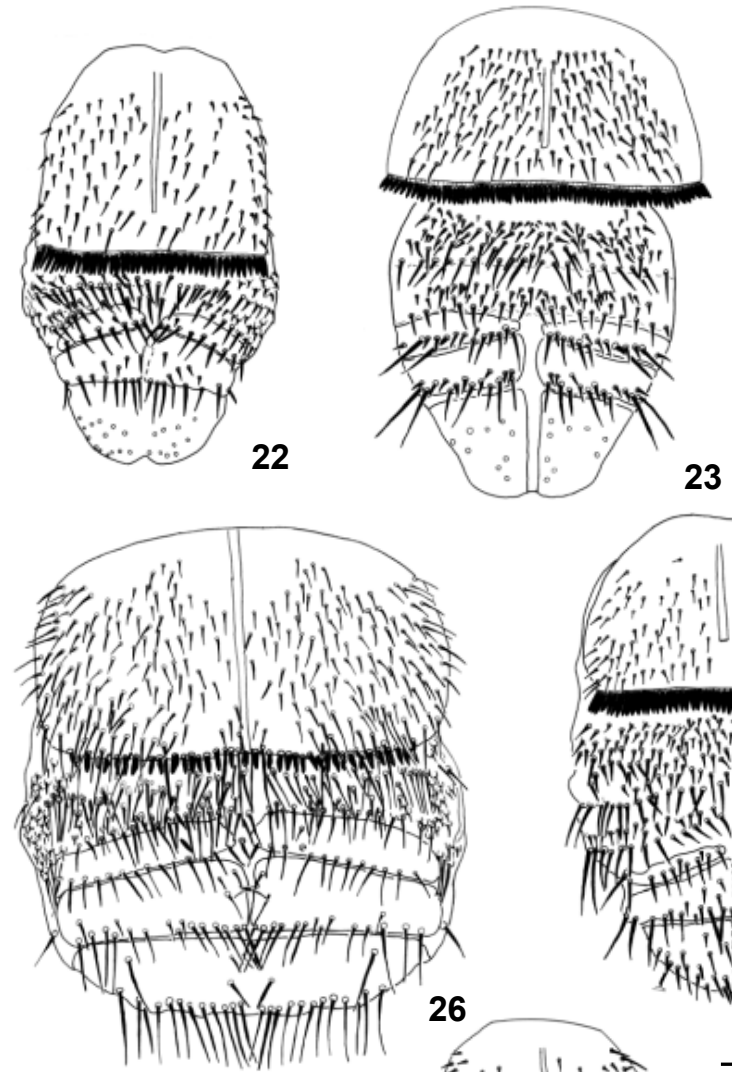

23
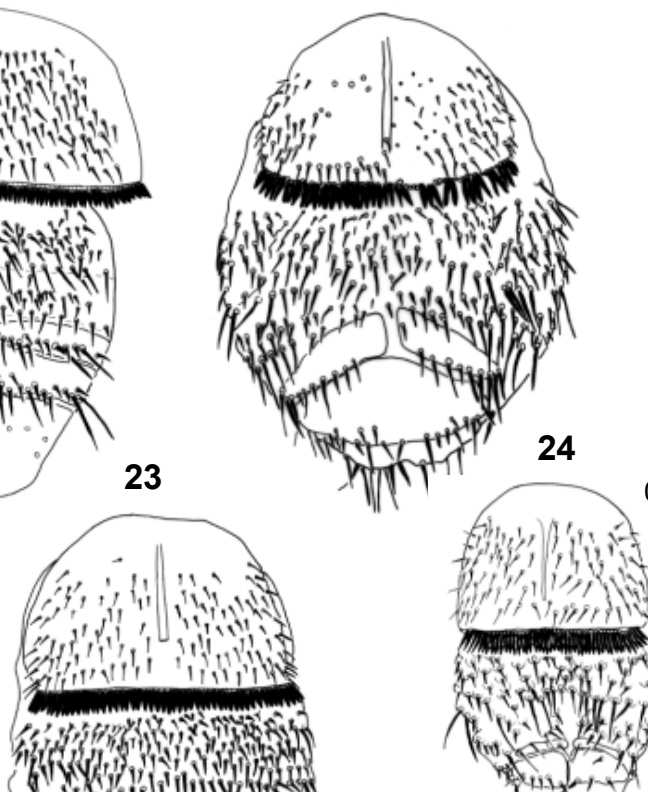

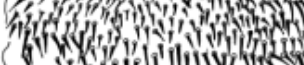
Roming 年 /

27
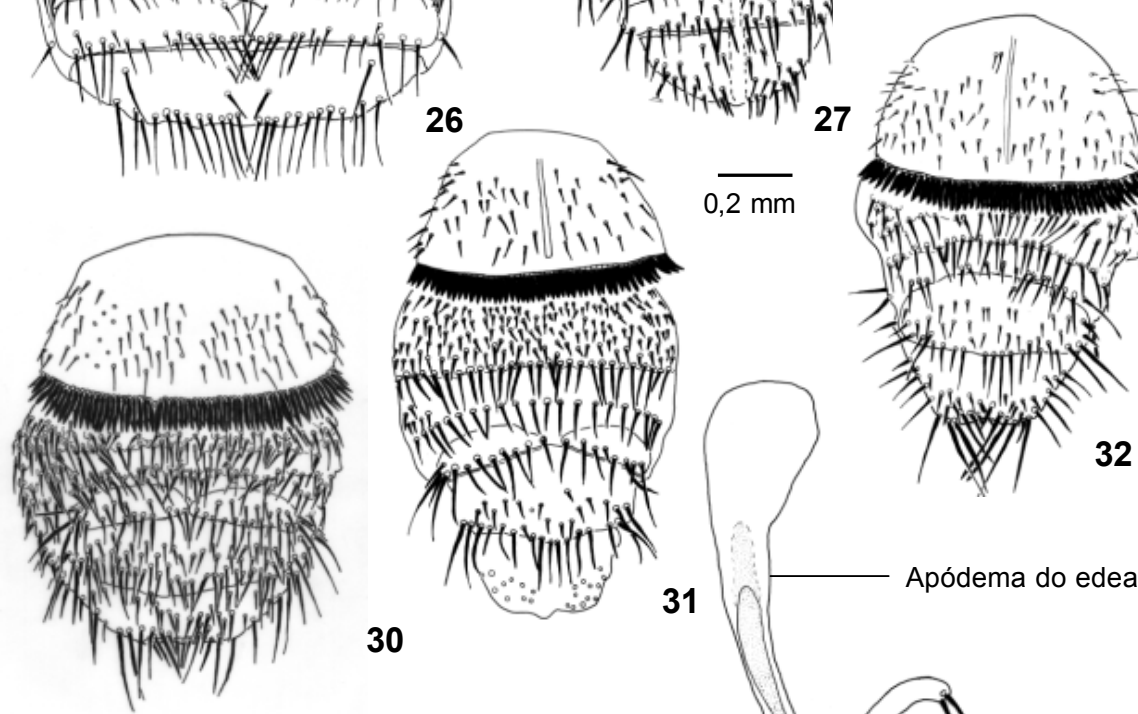

26 हैiv $0,2 \mathrm{~mm}$

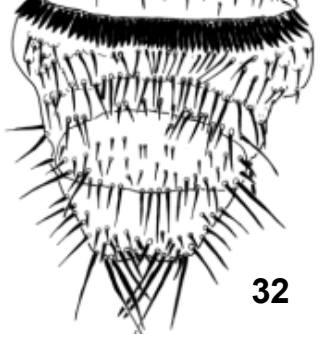

32
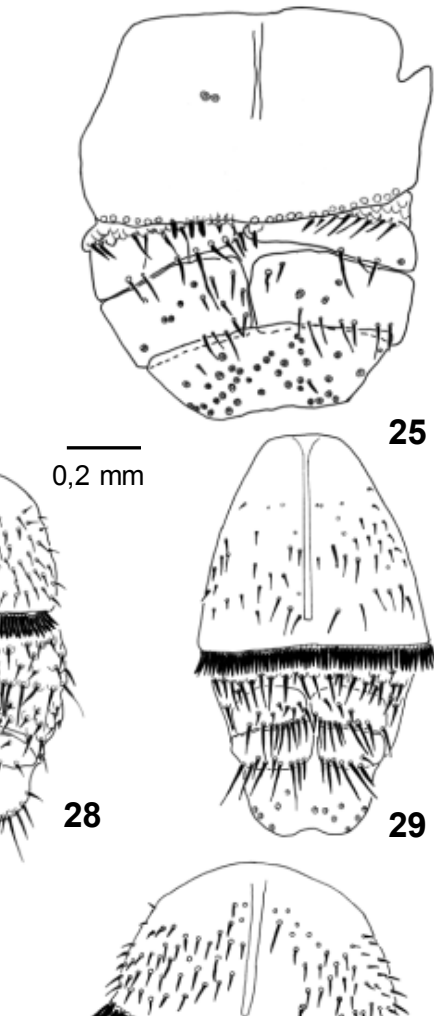

$0,2 \mathrm{~mm}$

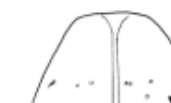

25

31

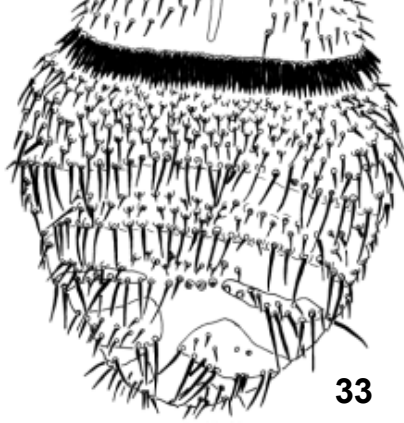

30

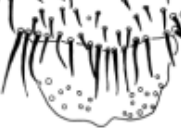

31

Apódema do edeago

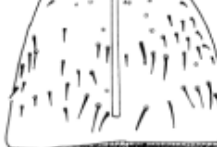

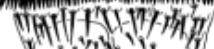

Hoton intitis

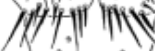

\section{9}

33

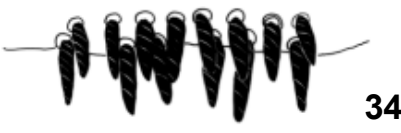

$0,2 \mathrm{~mm}$

34

Parâmero

Figuras 22-35. (22-29) Abdômen de Basilia, fêmea em vista ventral: (22) B. andersoni, parátipo, modificado de GraCiolu \& CARVALHO 2001; (23) Basilia carteri, modificado de Gracioll \& Carvalho (2001); (24) B. currani, holótipo; (25) B. hughscotti, holótipo; (26) B. hughscotti do Distrito Federal; (27) B. lindolphoi, modficado de Gracioll \& Carvalho (2001); (28) B. speiseri; (29) B. juquiensis, modificado de Gracioll \& Carvalho (2001); (30-33) abdômen da fêmea de Basilia, vista ventral: (30) B. ferruginea do Estado do Rio de Janeiro; (31) B. ortizi, modificado de Graciolli \& Carvalho (2001); (32) B. plaumanni; (33) B. ruige, modificado de Graciolli (2003); (34-35) macho de Basilia lindolphoi: (34) esternito V; (35) genitália, vista lateral. 
Macho. Abdômen - esternito II mais largo que longo, ctenídeo com setas espiniformes justapostas. Esternito V com oito setas espiniformes na região média da margem posterior. Edeago liso com ápice arredondado. Parâmero bifurcado.

Hospedeiro-tipo. Myotis nigricans (Vespertilionidae). Outros hospedeiros. Myotis riparius e Myotis sp. (Vespertilionidae).

Distribuição geográfica. Venezuela e Brasil (São Paulo, Paraná e Santa Catarina).

Material examinado. Paraná: Morretes (Parque Estadual Marumbi), 25/IX/1992, 1 fêmea (hosp. Myotis nigricans, DZUP); Foz do Iguaçu (Parque Nacional Iguaçu), 11/XII/1998, 1 fêmea (hosp. Myotis sp., DZUP), Sekiama leg.; 13/I/1999, 1 macho e 3 fêmeas (hosp. M. nigricans, DZUP), Graciolli, Lima \& Rocha leg.; Santa Catarina: Itapoá (Reserva Particular do Patrimônio Natural de Volta Velha), 20/II/2001, 2 machos e 3 fêmeas (hosp. M. nigricans, DZUP), G Graciolli leg., 11/XII/2001, 1 macho e 2 fêmeas (hosp. Myotis riparius, DZUP), G. Graciolli leg.

Comentário. Nova ocorrência para o Estado de Santa Catarina. Primeiro registro de B. juquiensis sobre M. riparius.

\section{Grupo ferruginea Basilia ferruginea Miranda-Ribeiro, 1903 Figs 17, 30, 38}

Basilia ferruginea Miranda-Ribeiro, 1903: 179, localidade-tipo: Sant'Ana do Sapé (atual Guidovaldo), Minas Gerais, Brasil; Guimarães \& D'Andretta, 1956: 28, figs 5, 6, 74; Guimarães 1966: 394 (registro); Theodor, 1967: 259 (diagnose).

Diagnose. Cabeça. Vértice com dois pares de setas e um par entre os olhos. Olhos bifacetados com base pigmentada.

Tórax. Notopleura com 12 setas. Sensila na margem anterior do fêmur II com duas setas sensoriais. Tíbias com quatro filas esculturadas de setas transversais sob sulcos na face ventral.

Fêmea. Abdômen - tergito I mais largo que longo, levemente fendido na linha média com poucas setas discais. Tergito II bilobado posteriormente, cada lóbulo com três a quatro setas espiniformes longas e 10 a 11 curtas. Segmento anal com margens laterais convergentes. Conetivo abdominal lateral com os ápices da setas ultrapassando a base das setas seguintes (Fig. 17). Esternito II mais largo que longo, ctenídeo com setas espiniformes justapostas. Esternitos VI e VII inteiros (Fig. 30).

Macho. Abdômen - esternito II mais largo que longo, ctenídeo com setas espiniformes justapostas. Esternito V com 30 a 40 setas espiniformes em duas filas na margem posterior. Parâmero com ápice arredondado. Edeago com margens dorsal e ventral serreadas.

Hospedeiro-tipo. Atalapha frantzii Dobson, 1878 ( = Lasiurus blossevillii) (Vespertilionidae). Outros hospedeiros. Lasiurus borealis, L. cinereus, L. pfeifferi (Vespertilionidae).

Distribuição geográfica. Cuba, Panamá, Equador (Galápagos); Brasil (Pará, Minas Gerais, Rio de Janeiro, São Paulo e Santa Catarina) e Paraguai.

Material adicional examinado. Rio de Janeiro: Rio de Ja- neiro, 1920, 1 fêmea (hosp. Lasiurus borealis [ = Lasiurus blossevillii], MZSP), L. Travassos leg.

Comentário. Espécie registrada por THEODOR (1967) no estado de Santa Catarina sobre uma espécie não determinada de morcego. Parasito exclusivo de morcegos do gênero Lasiurus.

\section{Basilia ortizi Machado-Allison, 1963 Figs $18,31,38$}

Basilia ortizi Machado-Allison, 1963: 455, localidade-tipo: Serranía de Nuria, Edo. Bolívar, Venezuela; Guimarães, 1972: 2 (registro); Guimarães, 1977: figs 3-5; Graciolli \& Carvalho, 2001: 41 (diagnose).

Diagnose. Cabeça. Vértice com dois pares de setas na margem anterior e um par anterior e entre os olhos. Olhos bifacetados.

Tórax. Notopleura com 10 setas. Mesonoto com expansão posterior digitiforme. Tíbias com três filas de setas transversais sob sulcos na face ventral.

Fêmea. Abdômen - tergito I pequeno, dividido posteriormente em dois pequenos lóbulos; cada lóbulo com oito setas longas. Tergito II sinuoso bilobado posteriormente, lóbulos estreitos e cada um com duas a três macrosetas e cinco a seis setas menores espiniformes. Segmento anal com margens laterais convergentes. Setas pustuladas do conetivo abdominal lateral curtas (Fig. 18). Esternito II mais largo que longo, ctenídeo com setas espiniformes justapostas. Esternito VI inteiro Esternito VII dividido ao meio (Fig. 31).

Macho. Abdômen - esternito II mais largo que longo, ctenídeo com setas espiniformes justapostas. Esternito V com 21 a 22 setas espiniformes na margem posterior. Parâmero com ápice pontiagudo. Edeago com margem dorsal serreada e ápice truncado.

Hospedeiro-tipo. Eptesicus melanopterus ( = Eptesicus fuscus) (Vespertilionidae). Outros hospedeiros. Artibeus hartii, Chrotopterus auritus (Phyllostomidae); Eptesicus brasiliensis, E. furinalis, Eptesicus sp. e Myotis riparius (Vespertilionidae).

Distribuição geográfica. Belize, Costa Rica, Venezuela e Brasil (Paraná).

Material examinado. Paraná: Bocaiúva do Sul (Caverna da Lancinha II), 10/XI/1987, 1 fêmea (hosp. Chrotopterus auritus, DZUP).

Comentário. Espécie com distribuição disjunta. O exemplar examinado por Graciolli \& CaRvalho (2001) ainda é o único registro desta espécie para o sul da América do Sul.

\section{Basilia plaumanni Scott, 1940 \\ Figs $1,2,5,17,32,39$}

Basilia plaumanni Scott, 1940: 58, localidade-tipo: Seara (Nova Teutônia), Santa Catarina, Brasil; Guimarães \& D'Andretta, 1956: figs 1, 2, 14-17; Theodor, 1967: 266 (diagnose); Peterson \& Maa, 1970: 1487 (registro); Graciolli \& Carvalho, 2001: 43 (diagnose).

Revista Brasileira de Zoologia 21 (4): 971-985, dezembro 2004 

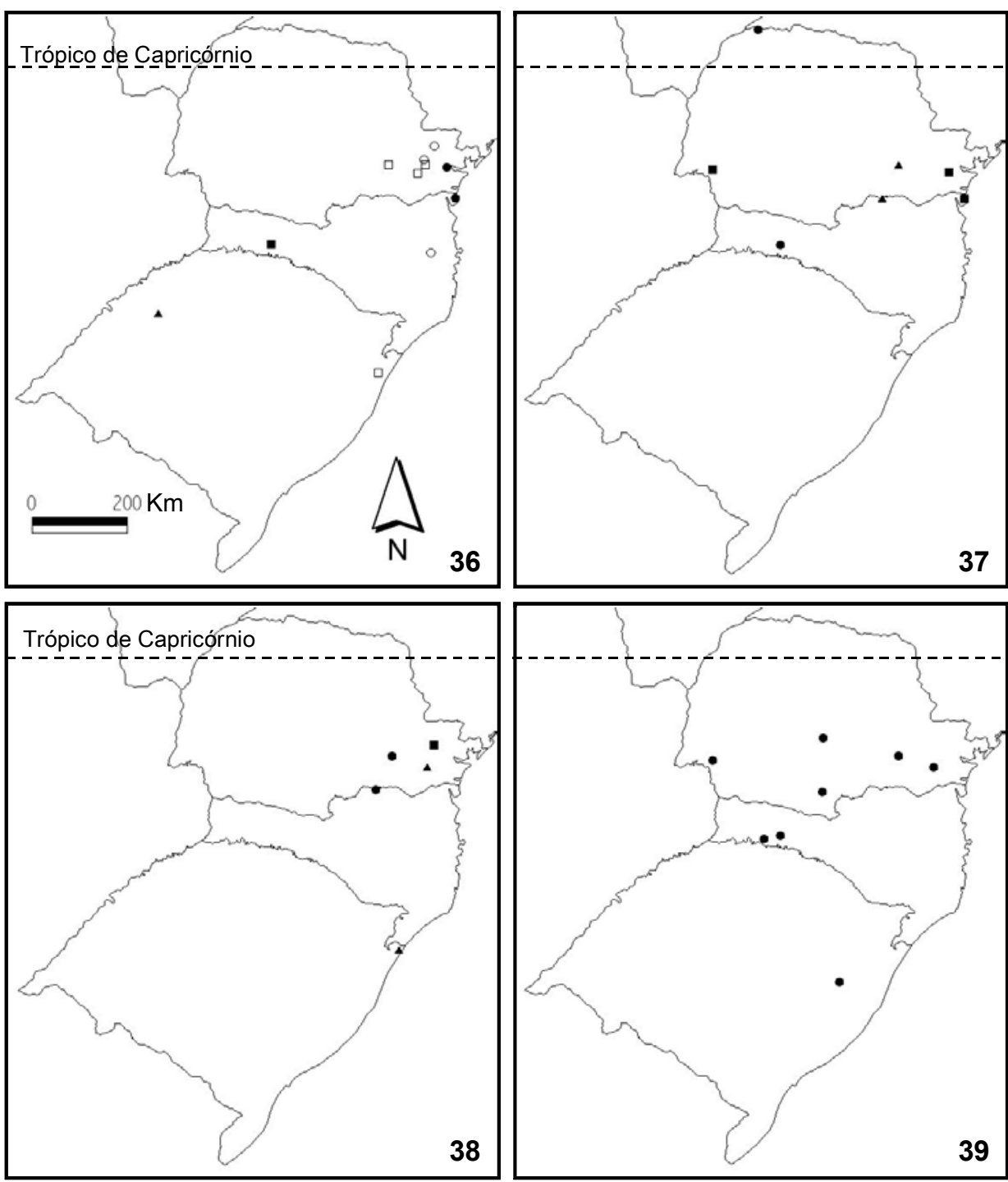

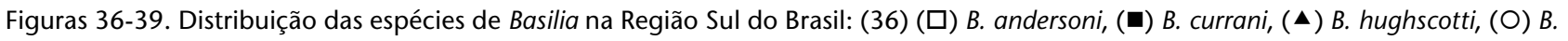

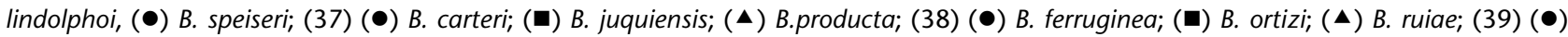
B. plaumanni.

Basilia mexicana; Guimarães 1946: 28 (redescrição). Erro de identificação.

Diagnose. Cabeça. Vértice com três pares de setas, um par entre os olhos compostos. Olhos compostos bifacetados.

Tórax. Notopleura com 11 a 12 setas. Mesonoto com elevação posterior conspícua. Sensila na margem anterior dos fêmures II e III com quatro a cinco e 13 a 14 setas sensoriais, respectivamente (Fig. 5). Tíbias com três filas de setas transversais sob sulcos na face ventral.

Fêmea. Abdômen - tergito I mais longo que largo, com pouca ou nenhuma seta discal. Tergito II sinuoso com poucas setas discais, bilobado posteriormente, cada lóbulo com uma a duas setas espiniformes longas e oito a 11 setas espiniformes curtas. Segmento anal com margens laterais convergentes. Conetivo abdominal lateral com setas curtas (Fig. 17). Esternito II mais longo que largo, ctenídeo com setas espiniformes justapostas. Esternitos VI e VII inteiros (Fig. 32).

Macho. Abdômen - esternito II mais longo que largo, ctenídeo com setas espiniformes justapostas. Esternito V na margem mediana posterior com 22 setas espiniformes. Parâmero pontiagudo. Edeago margem dorsal levemente serreada, com um processo ventral apical.

Revista Brasileira de Zoologia 21 (4): 971-985, dezembro 2004 
Hospedeiro-tipo. Histiotus velatus (Vespertilionidae). Outros hospedeiros. Eptesicus brasiliensis, E. fuscus, Histiotus macrotus, H. montanus, Histiotus sp. e Myotis nigricans (Vespertilionidae).

Distribuição geográfica. Brasil (Minas Gerais, São Paulo, Paraná, Santa Catarina e Rio Grande do Sul), Paraguai, Argentina (Jujuy, Santiago del Estero e Córdoba) e Uruguai.

Material examinado. Paraná: Bituruna (Fazenda Lageado Grande), 07/XII/1999, 1 fêmea (hosp. Histiotus velatus, MHNCI); Fazenda Rio Grande (Fazenda Gralha Azul), 07/XII/2002, 1 macho e 2 fêmeas (hosp. H. velatus, DZUP), G. Graciolli \& G. Bianconi leg.; Turvo (Chacará Edelweiss), 18/I/2000, 1 macho e 2 fêmeas (hosp. Eptesicus brasiliensis, MHNCI), M Miretzki leg.; Santa Catarina: Guatambú (Floresta Nacional de Chapecó), 26/ IV/1999, 4 machos e 9 fêmeas (hosp. Myotis nigricans, DZUP), Fortes leg.; Seara (Nova Teutônia), 1 macho e 2 fêmeas (hosp. indeterminado, MZSP), F. Plaumann leg.; Rio Grande do Sul: Porto Alegre, 03/II/1914, 1 macho (hosp. indeterminado, MCN).

Comentário. Novo registro para o Estado do Rio Grande do Sul. Entre os exemplares de Basilia plaumanni examinados por THEODOR (1967: 267), há uma fêmea coletada sobre Eptesicus fuscus no município de Palmeira, Paraná. Eptesicus fuscus é encontrada no norte dos Estados Unidos até o Norte da América do Sul (KurTa \& BAKer 1990). Esta espécie é morfologicamente semelhante à Eptesicus brasiliensis. Portanto, o hospedeiro do material examinado por THEODOR pode ser E. brasiliensis, uma espécie desconhecida para a ciência, ou mesmo $E$. fuscus. Basilia plaumanni é semelhante à Basilia silvae (Brèthes, 1913) e à Basilia neamericana Schuurmans-Stekhoven Jr., 1951, diferindo principalmente na forma e quetotaxia do Tergito II das fêmeas. Basilia plaumanni é encontrada no sul da América do Sul sobre espécies de Eptesicus Rafinesque, 1820, Histiotus Gervais, 1856 e Myotis Kaup, 1829. Basilia silvae está restrita ao Chile e parasita Histiotus montanus e Myotis chiloensis (GUIMARães \& D'ANDRETTA 1956, MuÑOZ et al. 2001). Enquanto Basilia neamericana ocorre apenas no norte da Argentina sobre Eptesicus furinalis e Eptesicus diminutus. Quando B. plaumanni e $B$. neamericana ocorrem simpatricamente, a primeira é encontrada somente sobre espécies de Histiotus e Myotis (Autino et al. 1999).

\section{Basilia producta Maa, 1968 Figs 20, 37}

Basilia plaumanni; Guimarães \& D'Andretta, 1956: 34 (part., registro). Erro de identificação.

Basilia producta Maa, 1968: 30, localidade-tipo: Palmeira, Paraná, Brasil; Graciolli \& Carvalho, 2001: 44 (diagnose).

Diagnose. Cabeça. Vértice com seis a oito setas anteriores e duas setas entre os olhos bifacetados. Olhos bifacetados com base pigmentada.

Tórax. Notopleura com oito a dez setas. Mesonoto sem elevação conspícua posterior. Sensila na margem anterior dos fêmures II e III com 12 a 13 e 31 setas sensoriais, respectivamente. Tíbias com três filas de setas transversais sob sulcos na face ventral.
Fêmea. Abdômen - tergito I com poucas setas discais e, na margem posterior, dois grupos com mais ou menos oito setas mais longas que o tergito. Tergito II sinuoso mais longo que amplo; bilobado posteriormente, cada lóbulo com três setas espiniformes longas e três setas espiniformes curtas. Segmento anal com margens laterais convergentes. Conetivo abdominal lateral com setas curtas (Fig. 20). Esternito II mais longo que largo, ctenídeo com setas espiniformes justapostas. Esternitos VI e VII inteiros.

Macho - desconhecido.

Hospedeiro-tipo. Myotis albescens (Vespertilionidae). Outro hospedeiro. Myotis nigricans (Vespertilionidae).

Distribuição geográfica: Brasil (Paraná e Santa Catarina).

Material examinado. Santa Catarina: Três Barras, 18/I/ 1954, 1 fêmea, hosp. Myotis nigricans, MZSP).

Comentário. Basilia producta foi descrita a partir de três fêmeas encontradas sobre um morcego fixado coletado no município de Palmeira, estado do Paraná, e este encontrava-se depositado no Museu de Gênova. Apenas o holótipo e os parátipos eram conhecidos. O exemplar identificado por nós como B. producta estava depositado no MZSP e havia sido identificado por Lindolpho R. Guimarães (Museu de Zoologia, Universidade de São Paulo) como Basilia plaumanni.

\section{Basilia ruiae Graciolli, 2003 Figs $4,8,21,33,38$}

Basilia sp., Graciolli et al., 2003: 403 (registro).

Basilia ruiae Graciolli, 2003: 4, localidade-tipo: Estação de Pesquisa e Produção de Maquiné da Fundação de Pesquisa Agropecuária da Secretaria de Agricultura do Estado do Rio Grande do Sul, Maquiné, Rio Grande do Sul, Brasil.

Diagnose. Cabeça. Vértice com 15 setas entre a margem anterior e os olhos. Olhos bifacetados sobre base pigmentada.

Tórax. Notopleura com 10 a 11 setas. Mesonoto elevado posteriormente. Tíbias com quatro filas de setas transversais sob sulcos na face ventral.

Fêmea. Abdômen - tergito I mais largo que longo. Tergito II dividido longitudinalmente e apicalmente em dois lóbulos com oito a 10 setas espiniformes longas e sete curtas. Conetivo abdominal dorsal com setas pustuladas entre o tergito II e o segmento anal. Segmento anal com margens laterais subparalelas. Conetivo abdominal lateral com setas curtas (Fig. 21). Esternito II mais longo que largo, ctenídeo com setas espiniformes justapostas. Esternito VI dividido em dois escleritos, lado interno mais longo que o lado externo (Fig. 33).

Macho. Abdômen - esternito II mais longo que largo, ctenídeo com setas espiniformes justapostas. Esternito V com 27 setas espiniformes dispostas em duas filas. Parâmero com ápice arredondado e 10 setas. Apódema do edeago curvado. Edeago com margens dorsal e ventral serreadas.

Hospedeiro-tipo. Myotis ruber (Vespertilionidae).

Distribuição geográfica. Brasil (São Paulo, Paraná e Rio Grande do Sul). 
Material examinado. Paraná: Fazenda Rio Grande (Fazenda Gralha Azul), 11/V/2002, 1 fêmea (parátipo, hosp. Myotis ruber, DZUP), G. Bianconi leg.; Rio Grande do Sul: Maquiné (Estação de Pesquisa e Produção de Maquiné da Fundação de Pesquisa Agropecuária da Secretaria de Agricultura do Estado do Rio Grande do Sul), 09/I/2001, 2 fêmeas (holótipo via líquida e parátipo em lâmina, hosp. M. ruber, DZUP), A.M. Rui leg.

Comentário. Espécie próxima às congenéricas que parasitam morcegos do gênero Lasiurus, $B$. ferruginea, $B$. handleyi e $B$. insularis.

\section{CONSIDERAÇÕES FINAIS}

As 12 espécies de Basilia encontradas na Região Sul do Brasil representam quase $60 \%$ das espécies encontradas no país, sendo que apenas $B$. producta é endêmica da região. É possível notar com os dados apresentados acima e com a tabela I e as figuras 36-39, que há um decréscimo no número de espécies de Basilia no sentido norte-sul. Este padrão pode ser resultado de um maior esforço de coleta nos estados do Paraná e de Santa Catarina ou de algum fator abiótico (clima, qualidade de abrigo, etc), pois as diferenças encontradas não podem ser explicadas pela disponibilidade do número de espécies hospedeiras pertencentes à família Vespertilionidae, que é semelhante nos três estados. No Paraná e no Rio Grande Sul foram registradas 13 espécies e em Santa Catarina 15 espécies (Miretzki 2003, Reis et al. 2002, RuI \& FABIÁN 1997).

Sete espécies de Basilia têm como limite meridional de distribuição o Estado de Santa Catarina e apenas B. ortizi tem seu limite no Paraná. Basilia plaumanni foi a única espécie encontrada nos três estados. No entanto, $B$. andersoni e $B$. ruiae poderão estar presentes em Santa Catarina, já que foram encontradas no Paraná e no Rio Grande do Sul. Já B. currani e B. ferruginea, que foram registradas somente em Santa Catarina, deverão ser coletadas no Paraná. Basilia hughscotti, registrada somente no oeste do Rio Grande do Sul, é encontrada também no centro do Brasil e poderá ser encontrada no Paraná e Santa Catarina.

Três das espécies de Basilia foram encontradas somente sobre uma espécie hospedeiro, desconsiderando-se as associações dúbias ou transitórias.

\section{Lista hospedeiro-parasito para Chiroptera e Basilia na Região Sul do Brasil ( ${ }^{\star}$ associação acidental ou errônea)}

\author{
Phyllostomidae \\ Phyllostominae \\ Chrotopterus auritus (Peters, 1856) \\ Basilia hughscotti Guimarães, 1946* \\ Basilia ortizi Machado-Allison, 1963* \\ Mimon bennettii (Gray, 1838) \\ Basilia lindolphoi Graciolli, 2001* \\ Vespertilionidae \\ Eptesicus brasiliensis (Desmarest, 1819) \\ Basilia carteri Scott, 1936 \\ Basilia plaumanni Scott, 1940
}

Tabela I. Ocorrência das espécies de Basilia Miranda-Ribeiro nos estados da Região Sul do Brasil.

\begin{tabular}{llll}
\hline \multirow{2}{*}{ Espécie } & \multicolumn{3}{c}{ Estado } \\
\cline { 2 - 4 } & Paraná Santa Catarina Rio Grande do Sul \\
\hline Grupo speiseri & & & $\mathrm{X}$ \\
B. andersoni & $\mathrm{X}$ & $\mathrm{X}$ & \\
B. carteri & $\mathrm{X}$ & $\mathrm{X}$ & $\mathrm{X}$ \\
B. currani & & & \\
B. hughscotti & & $\mathrm{X}$ & \\
B. lindolphoi & $\mathrm{X}$ & $\mathrm{X}$ & \\
B. speiseri & $\mathrm{X}$ & & \\
Grupo juquiensis & & $\mathrm{X}$ & \\
B. juquiensis & $\mathrm{X}$ & & \\
Grupo ferruginea & & $\mathrm{X}$ & \\
B. ferruginea & & & \\
B. ortizi & $\mathrm{X}$ & & $\mathrm{X}$ \\
B. plaumanni & $\mathrm{X}$ & $\mathrm{X}$ & 4 \\
B. producta & $\mathrm{X}$ & $\mathrm{X}$ & \\
B. ruiae & $\mathrm{X}$ & & \\
\hline Total & 9 & 8 & \\
\hline
\end{tabular}

Eptesicus fuscus (Beauvois, 1796)

Basilia plaumanni Scott, 1940

Histiotus velatus (I. Geoffroy, 1824)

Basilia andersoni Peterson \& Maa, 1970*

Basilia plaumanni Scott, 1940

Myotis albescens (E. Geoffroy, 1806)

Basilia producta Maa, 1968

Myotis nigricans (Schinz, 1821)

Basilia juquiensis Guimarães, 1946

Basilia lindolphoi Graciolli, 2001

Basilia plaumanni Scott, 1940

Basilia producta Maa, 1968

Myotis riparius Handley, 1960

Basilia juquiensis Guimarães, 1946

Myotis ruber (E. Geoffroy, 1806)

Basilia ruiae Graciolli, 2003

Myotis sp.

Basilia andersoni Peterson \& Maa, 1970

Basilia currani Guimarães, 1943

Basilia lindolphoi Graciolli, 2001

Basilia speiseri (Miranda-Ribeiro, 1907)

\section{AGRADECIMENTOS}

Ao CNPq (processo $\left.{ }^{\circ} 140214 / 00-3\right)$ pelo suporte financeiro. As seguintes pessoas que contribuíram de algumas forma com este trabalho, Michel Miretzki, Glédson V. Bianconi, 
Ana Maria Rui, Juliana Quadros, Liliane Tiepolo, Ives S. Arnoni, Lúcio Machado, Engenheiro Agronômo Guido Sander, Viviane Kananda. Aos seguintes curadores e suas Instituições pelo empréstimo de espécimens utilizados, Dra. Luciane Marinoni (DZUP), M. Sc. Márcia Árzua (MHNCI), Dra. Eliana Cancello e Dra. Mirian Marques (MZSP) e M. Sc. Hilda A. de O. Gastal (MCN). Aos Doutores Claudio José Barros de Carvalho, Arício Xavier Linhares, Luciane Marinoni, Marcela Lareschi e Walter A.P. Boeger pela discussão e comentários sobre o trabalho.

\section{REFERÊNCIAS BIBLIOGRÁFICAS}

Autino, A.G.; G.L. Claps \& R.M. Barquez. 1999. Insectos ectoparasitos de murcielagos de las Yungas de la Argentina. Acta Zoologica Mexicana, Mexico, 78: 119-169.

- 2000. Nuevos registros de Diptera (Nycteribiidae) y Siphonaptera (Ischnopsyllidae) de Chiroptera (Vespertilionidae) de la Argentina. Boletín de Entomologia Venezolana, Nueva Serie, Caracas, 15: 109-112.

Curran, C.H. 1935. New species of Nycteribiidae and Streblidae (Diptera). American Museum Novitates, New York, 765 : $1-15$.

Del Ponte, E. 1944. Basilia romañai, nobis de la Argentina. Anales del Instituto de Medicina Regional, Universidad de Tucuman, Reisitencia, 1: 117-128.

FERRIS, G.F. 1924. The New World Nycteribiidae. Entomological News, Philadelphia, 35: 191-199.

GraCiolLI G 2001. Distribuição geográfica e hospedeiros quirópteros (Mammalia, Chiroptera) de moscas nicteribidas americanas (Diptera, Nycteribiidae). Revista Brasileira de Zoologia, Curitiba, 18 (Supl. 1): 307-322.

. 2003. Two new species of Basilia Miranda-Ribeiro, 1903 (Diptera: Nycteribiidae), members of the ferruginea group, from Southern Brazil. Zootaxa, Auckland, 261: 1-7. Graciolli, G. \& L.S. Aguiar. 2002. Ocorrência de moscas ectoparasitas (Diptera, Streblidae e Nycteribiidae) de morcegos (Mammalia, Chiroptera) no Cerrado de Brasília, Distrito Federal, Brasil. Revista Brasileira de Zoologia, Curitiba, 19 (Supl. 1): 177-181.

Graciolli, G. \& E. Bernard. 2002. Novos registros de moscas ectoparasitas (Diptera, Streblidae e Nycteribiidae) em morcegos (Mammalia, Chiroptera) do Amazonas e Pará, Brasil. Revista Brasileira de Zoologia, Curitiba, 19 (Supl. 1): 77-86.

Graciolli, G. \& C.J.B. de Carvalho. 2001. Moscas ectoparasitas (Diptera, Hippoboscoidea, Nycteribiidae) de morcegos (Mammalia, Chiroptera) do Estado do Paraná. I. Basilia, taxonomia e chave pictórica para as espécies. Revista Brasileira de Zoologia, Curitiba, 18 (Supl. 1): 33-49.

Graciolli, G.; F.C. Passos; W.A. Pedro \& B.K. Lim. 2003 [2002]. Records of Streblidae and Nycteribiidae (Diptera) on vespertilionid bats (Chiroptera: Vespertilionidae) from São Paulo State, Brazil. Journal of the New York Entomological Society, New York, 110: 402-404.
Gregorin, R. \& V.A. TADDEI. 2002. Chave artificial para a identificação de molossídeos brasileiros (Mammalia, Chiroptera). Mastozoologia Neotropical, Mendonza, 9: 13-32.

GuIMARãES, L.R. 1943. Mais uma nova espécie sulamericana de Nycteribiidae. Papéis Avulsos do Departamento de Zoologia do Estado de São Paulo, São Paulo, 3: 257-260.

. 1946. Revisão das espécies Sul-americanas do gênero Basilia (Diptera - Nycteribiidae). Arquivos de Zoologia do Estado de São Paulo, São Paulo, 5: 1-88.

- 1966. Nycteribiid batflies from Panama (Diptera: Nycteribiidae), p. 393-404. In: R.L. WENZEL \& V.J. TiPTON (Eds). Ectoparasites of Panama. Field Museum of Natural History, Chicago, XII+861p.

. 1972. Venezuelan nycteribiid batflies (Diptera: Nycteribiidae). Brigham Young University Science Bulletin, Biological Series, Provo, 17: 1-11.

- 1977. Supplementary note on Venezuelan batflies (Diptera: Nycteribiidae). The Great Basin Naturalist, Provo, 37: 221-224.

Guimarães, L.R. \& M.A.V. D'Andretta. 1956. Sinopse dos Nycteribiidae (Diptera) do Novo Mundo. Arquivos de Zoologia do Estado de São Paulo, São Paulo, 10: 1-184.

Koopman, K.F. 1993. Order Chirotera, p. 137-241. In: D.L. WILSON \& D.M. REeDER (Eds). Mammals species of the world. A taxonomic and geographic reference. Washington, D.C., Smithsonian Institution Press, $2^{\text {nd }}$ ed., 1206p.

Kurta, A. \& R.H. Baker. 1990. Eptesicus fuscus. Mammalian species, New York, 356:1-10.

MAA, T.C. 1968. New Basilia species from Thailand, Mexico and Brazil (Diptera: Nycteribiidae). Pacific Insects, Honolulu, 10: $25-32$.

- 1989. Family Nycteribiidae, p. 790-794. In: N.L. Evenhuis (Ed.). Catalog of the Australasian and Oceanic Regions. Honolulu, Bishop Museum Press and E.J. Brill, Bishop Special Publication 86, 1150p.

Machado-Allison, C.E. 1963. Un nuevo Nycteribiidae (Diptera) de Venezuela. Acta Biologica Venezuelica, Caracas, 3: 455459.

Miranda-Ribeiro, A. 1903. Basilia ferruginea genero novo e especie nova da familia dos Nycteribias. Archivos do Museu Nacional, Rio de Janeiro, 12: 175-179.

. 1907. Alguns dípteros interessantes. Archivos do Museu Nacional, Rio de Janeiro, 14: 231-239.

Miretzki, M. 2003.Morcegos do Estado do Paraná, Brasil (Mammalia, Chiroptera): riqueza de espécies, distribuição e síntese do conhecimento. Papéis Avulsos de Zoologia, São Paulo, 43: 101-138.

Muñoz, L.S.; D.A. González \& I. Fernández. 2001. Primer registro de Basilia silvae (Diptera: Nycteribiidae) sobre Histiotus montanus (Chiroptera: Vespertilionidae) en Chile. Gayana, Concepcion, 65: 221-222.

Peterson, B.V. 1960 [1959]. New distribution and host records for bats flies, and a key to the North American species of 
Basilia Ribeiro (Diptera: Nycteribiidae). Proceedings of the Entomological Society of Ontario, Ontario, 90: 30-37. - 1971. Notes on the bat flies of Costa Rica (Diptera: Nycteribiidae). Contributions in Science, Los Angeles, 212: 1-8.

Peterson, B.V. \& L.A. Lacey 1985. A new species of Hershkovitzia (Diptera: Nycteribiidae) from Brazil, with a key to the described species of the genus. Proceedings of the Entomological Society of Washington 87: 578-582.

Peterson, B.V. \& T.C. MaA 1970. One new and one previously unrecorded species of Basilia (Diptera: Nycteribiidae) from Uruguay. The Canadian Entomologist, Ottawa, 102: 1480-1487.

Peterson, B.V. \& R.L. Wenzel. 1987. Nycteribiidae, p. 1283-1291. In: J.F. McAlpine; B.V. Peterson; G.E. Shewell; H.J. Tekey; J.R Vockeroth \& D.M. Wood (Eds). Manual of Neartic Diptera. Ottawa, Research Branch Agriculture Canada, vol. 2, 1332p.

Reis, N.R. dos; A.L. Peracchi \& I.P. de Lima. 2002. Morcegos da bacia do Rio Tibagi, p. 251-279. In: M.E. Medri; E. BIANCHINI, A.O. Shibatta \& J.A. Pimenta (Eds) A bacia do Rio Tibagi. Londrina, Edição dos editores, 595p.

RUI, A.M. \& M.E. FABIÁN. 1997. Quirópteros de la Família Phyllostomidae (Mammalia, Chiroptera) en selvas del Estado de Rio Grande do Sul, Brasil. Chiroptera Neotropical, Brasília, 3: 219-471.

SChuUrmans-Stekhoven Jr., J.H. 1951a. Algunas especies del género
"Basilia" Ribeiro y creacion del nuevo género "Guimarãesia". Acta Zoologica Lilloana, Tucumán, 12: 101-115.

. 1951b. Nuevos hechos con Guimarãesia romañai (Del Ponte). Acta Zoologica Lilloana, Tucumán, 12: 551-561.

Scotт, H. 1936. Descriptions and records of Nycteribiidae, with a discussion of the genus Basilia. Journal of the Linnean Society of London, Zoology, London, 39: 479-505.

Sсотт, H. 1940. Nycteribiidae from Southern Brazil (Diptera). Proceedings of the Royal Entomological Society of London (B), London, 9: 57-61.

SPEISER, P. 1901. Ueber die Nycteribiiden, Fledermausparasiten aus der Gruppe der pupiparen Dipteren. Archiv Fur Naturgeschichte, Berlin, 67: 11-78.

. 1908. Die geographische Verbreitung der Diptera pupipara und ihre Phylogenie. Zeitschrift für wissenschaftliche Insektenbiologie, Berlin, 4: 437-447.

Theodor, O. 1967. An illustrated catalogue of the Rothschild collection of Nycteribiidae (Diptera) in the British Museum (Natural History) with keys and the short descriptions for the identification of subfamilies, genera, species and subspecies. British Museum (Natural History) Publication, London, 665: 1-506.

WhitAKER JR., J.O. \& R.E. Mumford. 1977. Records of ectoparasites from Brazilian mammals. Entomological News, Philadelphia, 88: 255-258.

Recebido em 13.IV.2004; aceito em 17.XI.2004. 